\title{
Grand challenges in glass science
}

\author{
John C. Mauro* \\ Science and Technology Division, Corning Incorporated, Corning, NY, USA \\ *Correspondence: mauroj@corning.com \\ Edited and reviewed by: \\ Yuanzheng Yue, Aalborg University, Denmark
}

Keywords: glass, glass transition, condensed matter physics, modeling and simulation

\section{INTRODUCTION}

Glass science offers researchers an ample range of open questions, starting from one of the most difficult problems in science: the basic nature of the glassy state.

Atomic-level descriptions of the glassy state are extremely complex due to the lack of long-range order found in crystalline materials. Our understanding of fundamental glass physics and chemistry is also hindered by the non-equilibrium thermodynamic state of glass. Recent theoretical and experimental advances are enabling the field to mature from an empirical discipline to one built upon rigorous scientific principles. These advancements not only offer a remarkable level of understanding but also contribute to the atomic-level design of novel functional glasses (Mauro et al., 2013a).

Glass science combines the cutting edge of a multitude of technical subjects: physics, chemistry, geology, engineering, and mathematics. Glass transition and relaxation phenomena are at the frontiers of condensed matter and statistical physics. From a chemical perspective, a nearly infinite combination of compositions can lead to successful glass formation. To facilitate progress at a large scale and exploit all of the unique properties that glasses may offer, the boundaries of glass engineering technology must also be pushed forward.

Recent advances of the domain have coincided with an unprecedented demand for glass as a high-tech material in consumer electronic devices. Working in the field of glass has never been more stimulating - glass plays a critical role in solving several of the global energy and healthcare challenges of today.

\section{GLASS PHYSICS}

Glass is in a state of thermodynamic disequilibrium and is continually relaxing toward a stable or metastable liquid phase, a transition reported to be one of the most intriguing problems in physics (Ediger et al., 1996; Phillips, 1996; Debenedetti and Stillinger, 2001; Dyre, 2006; Mauro et al., 2008). Glass transition and relaxation effects play a vital role in determining the property evolution of all glass compositions. While significant progress has been made in understanding glass transition and relaxation phenomena, key aspects, e.g., the structural origins of particular relaxation modes in glass and the interrelationships among the various relaxation modes, remain to be described, in addition to the relationship between structural relaxation and stress relaxation and the origin of low temperature relaxation modes (Welch et al., 2013).

We gain insight into glass transition and relaxation through statistical modeling (Mauro, 2013; Mauro and Smedskjaer, 2014), which can capture both the non-equilibrium and non-ergodic aspects of the glassy state. However, we still need to connect detailed statistical approaches to simplified thermodynamic ones properly accounting for the out-of-equilibrium character of the system. The traditional concept of fictive temperature distributions has shown to be generally invalid; except for the special case of a discontinuous glass transition (Mauro et al., 2009a).

The composition dependence of several glass properties can be predicted using the topological constraint theory (Boolchand et al., 2005; Micoulaut and Phillips, 2007; Mauro, 2011; Bauchy et al., 2013), capturing key physics governing the glassy state without irrelevant details. The theory has already been used in the design of new commercial glass compositions (Smedskjaer et al., 2010, 2011; Mauro et al., 2013a). It needs to be extended though to new glass composition families and to calculate additional properties.

A particularly challenging glass and glass-forming liquid characteristic is viscosity since it varies by orders of magnitude with temperature and is highly sensitive to thermal history (Mauro et al., 2009b,c). Recent progress built upon topological constraint theory has improved descriptions of both the thermal and compositional effects on viscosity (Mauro et al., 2013b). However, more detailed investigations are required to understand the role of fragility (Angell, 1991), i.e., the steepness of the viscosity curve at the glass transition, in governing relaxation behavior and other properties such as diffusion, as well as the structural origin of the fragile-tostrong transition (Zhang et al., 2010) and any associated liquid-liquid critical point (Lascaris et al., 2014).

The connection between fragility and the kinetics of nucleation and crystal growth in glass and glass-forming liquids (Fokin et al., 2010) is still poorly understood from the perspective of fundamental physical models. The thermodynamics of crystallization are also of critical concern, as quantified by the liquidus temperature of the system (Wallenberger and Smrcek, 2010). Liquidus temperature and phase equilibrium diagrams are of vital importance for all aspects of glass formation; however, there is currently no predictive model derived from fundamental physical considerations.

Glassy materials have always been prized for their favorable optical properties ( $\mathrm{Li}$ et al., 2010; Ballato and Dragic, 2013). While Maxwell's equations for electrodynamics are well understood, many challenges remain related to the origin of particular optical, electrical, and magnetic properties of glassy materials, such as glass structural effects on Brillouin 
scattering and photoelasticity (Guignard et al., 2007).

Additional research is also required to address the detailed origins of thermal properties such as heat capacity (Yue, 2008) and thermal expansion coefficient (Potuzak et al., 2010). Thermal conductivity (Yu and Freeman, 1987) and acoustic properties (Rufflé et al., 2006) of glass represent largely unexplored territories, both ripe for new research efforts.

\section{GLASS CHEMISTRY}

The lack of crystallinity in glass means that stoichiometric requirements of crystalline solids need no longer be satisfied. As a result, glass compositions are infinitely tunable in chemistry, opening the possibilities for uniquely refined combinations of properties (Varshneya, 2006). When designing new glass compositions, nearly the whole periodic table is available to serve as the palette of possible ingredients.

Silicates are certainly the most prominent glasses, both as naturally occurring geological systems and as manmade glass products. Despite their ubiquity, silicate glasses have complex structures (Mysen and Richet, 2005; Zheng et al., 2012) that are still only partially understood. Improvements in our understanding of structure-property relationships as a function of silicate glass chemistry will be of great value in the design and discovery of new industrial glasses (Mauro et al., 2014).

Other oxides such as borates (Kamitsos and Chryssikos, 1991) and phosphates (Brow, 2000) offer both interesting scientific challenges and promising technological opportunities beyond silicates. Unique effects can obtained when incorporating these other network-forming oxides into a silicate glass matrix (Greaves and Sen, 2007; Hubert and Faber, 2014), which provides a further area for future investigation.

Research in non-oxide glasses, such as bulk metallic and chalcogenide glasses, has exploded in recent decades (Boolchand et al., 2001, 2005; Greer and Ma, 2007; Schroers, 2013). Metallic glasses offer fascinating properties such as a brittle-toductile transition yielding a dramatically increased fracture toughness (Chen, 1976). Chalcogenide glasses are particularly interesting for their unique optical properties for infrared optics and photonics
(Zakery and Elliott, 2003). These composition families have challenged the traditional notion of what constitutes a glass, inspiring the research community to think more broadly about the possibilities of completely new glass chemistries.

Glass-ceramics (Zanotto, 2010, 2013; Höland and Beall, 2012), i.e., glasses with embedded crystallites formed through controlled nucleation and crystal growth, are an important research area as well. Their properties are not only dependent on glass and crystallite chemistry but also on the morphology and the distribution of the crystallites. Glass-ceramics can exhibit both high strength and toughness, often with low coefficients of thermal expansion. Researchers aim to achieve glass-ceramics having both high toughness and a high degree of transparency (Pinckney, 1999).

Polyamorphism (Huang et al., 2004; McMillan, 2004) is a recently discovered phenomenon: two glasses of identical chemistries may display markedly different short-range structural ordering, which leads to large differences in observed properties. The glass community is still at the initial stages of investigating which glass chemistries may exhibit this intriguing effect.

While most attention in the glass research community is on bulk glass structure and properties, whose modeling already poses special challenges due to the broad spatial and time scales to obtain sufficient statistics needed for accurate calculation of glass structure and properties, glass surfaces present distinct questions to answer. Bulk glass chemistry is not generally transferable to its surface (Pantano et al., 1975).

Finally, the chemical durability of glass is of great concern for such diverse application areas as nuclear waste storage, pharmaceutical glass labware, and glasses for long-term outdoor applications in photovoltaics, architecture, and the automotive industry; hence, there is an urgent need to develop a rigorous fundamental understanding of the thermodynamics and kinetics of the chemical durability of glass (Conradt, 2007).

\section{GLASS ENGINEERING TECHNOLOGY}

Glass forming process technology has proven to provide several of the most significant breakthroughs in the field
(Pilkington, 1969; Graham and Shuldiner, 2001; Varshneya, 2006). It is, therefore, essential to treat advances in glass engineering technology on an equal footing as advances in glass science.

The ribbon machine was crucial for mass production of glass envelopes for incandescent light bulbs, enabling affordable electrical lighting across the globe. The development and fine-tuning of the outside vapor deposition was essential for the invention of low-loss glass fibers for optical communications, which directly led to the invention of the Internet and brought society into the Information Age. The Pilkington float process enabled the production of large, flat, high-quality, low-cost glass sheets for modern homes and skyscrapers. Finally, the fusion draw process has led to the development of high-precision, ultrathin specialty glass substrates for flat panel displays (Ellison and Cornejo, 2010).

The detailed chemistry of glass melting and fining is still a topic of great interest (Beerkens, 2001); entirely new approaches could offer dramatic benefits for large-scale glass production (Watanabe et al., 2010). Chemical interactions between molten glass and the refractory materials during melting and forming are also critically important. The community needs to better understand volatilization and condensation reactions during glass production. Homogenization of the glass during melting is a complicated process, but essential for obtaining desired properties (Bhosle et al., 2012).

Another intriguing possibility is the formation of glass under high pressure (Wondraczek and Mauro, 2009; Youngman, 2014). This occurs in volcanic and magmatic systems; however, current glass production is normally performed at ambient pressure. Application of high pressure can continuously alter the state of the glass, providing unique combinations of properties not accessible by adjusting thermal history alone.

\section{PIONEERING THE POSSIBILITIES OF GLASS}

The pace of innovation in glass science has increased enormously in recent decades (Mauro and Zanotto, 2014) due to the advances in our fundamental knowledge of glass physics and chemistry (Wondraczek and Mauro, 2009). Further emphasis on 
fundamentals will be key in laying the groundwork for the next wave of innovation in glass as a highly engineered material for addressing some of the greatest challenges facing the world today.

From glass windows to glass lenses in telescopes and microscopes, new developments in glass science and technology have been key enablers of modern civilization throughout history. This societal impact has not diminished; the use of glasses for liquid crystal display panels and damageresistant protective covers has transformed the way in which humans interact with computing devices (Ellison and Cornejo, 2010).

A glass's resistance to breakage is key for a large number of practical applications. High-strength glasses are available (Varshneya, 2010; Wondraczek et al., 2011); however, even with chemical strengthening, they are still below the theoretical strength aimed for in defect-free conditions (Mattos, 2013). To approach the theoretical limit, understanding crack formation (Wiederhorn et al., 2013) and fracture behavior (Quinn, 2012; Bouchaud, 2013) is necessary. Further research should also aim to improve the ductility and fracture toughness of glass (Shi et al., 2014), which are intimately connected to the Poisson's ratio of the material (Greaves et al., 2011).

Glasses have also found novel applications in healthcare (Hench and Thompson, 2010; Hench et al., 2010; Fu et al., 2011; Jones and Clare, 2012). Bioactive glasses and glass-ceramics are now commonly used in the dental community and can also be used to promote bone regeneration. A new generation of borate glass fibers has demonstrated effective healing of soft tissue (Rahaman et al., 2011). Radioactive glass microspheres have contributed to the fight against cancer (White and Day, 1994). An anti-microbial cover glass has recently been developed to suppress the spread of infectious diseases (Kosik Williams et al., 2014). The next generation of bioactive glassy materials may play a role in stem cell engineering (Hench and Thompson, 2010) by the activation of specific genes within living cells.

The demand for internet communication bandwidth continues to rise; optical interconnects made of glass and other glass-based photonic devices will be essential for controlling the flow of information in the next generation of information technology (Richardson et al., 2010; Li et al., 2014).

Glass will also play a crucial role in solving many of our challenges related to energy and the environment. Glass is already a key component in photovoltaics and other systems for solar energy conversion (Deubener et al., 2009). Glass components will also be critical for enabling new sustainable energy sources and facilitating access to clean air and water (Brow and Schmitt, 2009). Glass is also essential for the safe storage of radioactive waste materials from nuclear power generation (Jantzen et al., 2010).

For those inspired to learn more about this material of the future that continues to pose challenges to basic research and enables an unprecedented technological advancement, we recommend to continue reading the upcoming articles in the Glass Science specialty of Frontiers in Materials, as well as other recent reviews on the topic (Bange and Weissenberger-Eibl, 2010; Hench, 2011; Mauro and Zanotto, 2014; Mauro et al., 2014).

\section{ACKNOWLEDGMENTS}

I am grateful for many valuable discussions on the future of glass science with L. David Pye of Alfred University, Edgar D. Zanotto of the Federal University of São Carlos, and Michael S. Pambianchi, Daniel J. Vaughn, Adam J. Ellison, Douglas C. Allan, Jeffrey T. Kohli, Jean-Jacques Theron, Monique Comte, M. K. Badrinarayan, Gary S. Calabrese, and David L. Morse of Corning Incorporated. I am also thankful for many valuable conversations with participants at the Corning Glass Summit, held on June 12-13, 2014, in Corning, NY, USA.

\section{REFERENCES}

Angell, C. A. (1991). Relaxation in liquids, polymers and plastic crystals - strong/fragile patterns and problems. J. Non Cryst. Solids 13, 13-31. doi:10. 1016/0022-3093(91)90266-9

Ballato, J., and Dragic, P. (2013). Rethinking optical fiber: new demands, old glasses. J. Am. Ceram. Soc. 96, 2675-2692. doi:10.1111/jace.12516

Bange, K., and Weissenberger-Eibl, M. (2010). Making Glass Better: An ICG Roadmap with a 25 Year Glass R\&D Horizon. Madrid: International Commission on Glass.
Bauchy, M., Micoulaut, M., Boero, M., and Massobrio, C. (2013). Compositional thresholds and anomalies in connection with stiffness transitions in network glasses. Phys. Rev. Lett. 110, 165501. doi:10.1103/PhysRevLett.110.165501

Beerkens, R. G. C. (2001). Modeling and kinetics of volatilization from glass melts. J. Am. Ceram. Soc. 84, 1952-1960. doi:10.1111/j.1151-2916.2001. tb00942.x

Bhosle, S., Gunasekera, K., Boolchand, P., and Micoulaut, M. (2012). Melt homogenization and self-organization in chalcogenides-Part I. Int. J. Appl. Glass Sci. 3, 189-204. doi:10.1111/j.20411294.2012.00093. $\mathrm{x}$

Boolchand, P., Georgiev, D. G., and Goodman, B. (2001). Discovery of the intermediate phase in chalcogenide glasses. J. Optoelectron. Adv. Mater. 3 , 703-720.

Boolchand, P., Lucovsky, G., Phillips, J. C., and Thorpe, M. F. (2005). Self-organization and the physics of glassy networks. Philos. Mag. 85, 3823-3838. doi:10.1080/14786430500256425

Bouchaud, E. (2013). The breaking of brittle materials. Phys. Online 6, 50. doi:10.1103/Physics.6.50

Brow, R. K. (2000). Review: the structure of simple phosphate glasses. J. Non Cryst. Solids 26, 1-28. doi:10.1016/S0022-3093(99)00620-1

Brow, R. K., and Schmitt, M. L. (2009). A survey of energy and environmental applications of glass. J. Euro. Ceram. Soc. 29, 1193-1201. doi:10.1021/ ar200070w

Chen, H. S. (1976). Ductile-brittle transition in metallic glasses. Mat. Sci. Eng. 26, 79-82. doi:10.1063/1. 4812281

Conradt, R. (2007). Chemical durability of oxide glasses in aqueous solutions: a review. J. Am. Ceram. Soc. 91, 728-735. doi:10.1111/j.1551-2916.2007. 02101.x

Debenedetti, P. G., and Stillinger, F. H. (2001). Supercooled liquids and the glass transition. Nature 410, 259-267. doi:10.1038/35065704

Deubener, J., Helsch, G., Moiseev, A., and Bornhöft, H. (2009). Glasses for solar energy conversion systems. J. Euro. Ceram. Soc. 29, 1203-1210. doi:10.1016/j. jeurceramsoc.2008.08.009

Dyre, J. C. (2006). Colloquium: the glass transition and elastic models of glass-forming liquids. Rev. Mod. Phys. 78, 953-972. doi:10.1103/RevModPhys. 78.953

Ediger, M. D., Angell, C. A., and Nagel, S. R. (1996). Supercooled liquids and glasses. J. Phys. Chem. 100, 13200-13212. doi:10.1021/jp953538d

Ellison, A. J., and Cornejo, I. A. (2010). Glass substrates for liquid crystal displays. Int. J. Appl. Glass Sci. 1, 87-103. doi:10.1111/j.2041-1294.2010. 00009.x

Fokin, V. M., Zanotto, E. D., and Schmelzer, J. W. P. (2010). On the thermodynamic driving force for interpretation of nucleation experiments. J. Non Cryst. Solids 356, 2185-2191. doi:10.1016/j. jnoncrysol.2010.07.040

Fu, Q., Saiz, E., Rahaman, M. N., and Tomsia, A. P. (2011). Bioactive glass scaffolds for bone tissue engineering: state of the art and future perspectives. Mat. Sci. Eng. 31, 1245-1256. doi:10.1016/j. msec.2011.04.022 
Graham, B., and Shuldiner, A. (2001). Corning and the Craft of Innovation. New York: Oxford University Press.

Greaves, G. N., Greer, A. L., Lakes, R. S., and Rouxel, T. (2011). Poisson's ratio and modern materials. Nat. Mater. 10, 823-837. doi:10.1038/nmat3134

Greaves, G. N., and Sen, S. (2007). Inorganic glasses, glass-forming liquids and amorphizing solids. $A d v$. Phys. 56, 1-166. doi:10.1080/00018730601147426

Greer, A. L., and Ma, E. (2007). Bulk metallic glasses: at the cutting edge of metals research. MRS Bull. 32, 611-619. doi:10.1557/mrs2007.121

Guignard, M., Albrecht, L., and Zwanziger, J. W. (2007). Zero-stress optic glass without lead. Chem. Mater. 19, 286-290. doi:10.1021/cm062208a

Hench, L. L. (2011). Glass and glass-ceramic technologies to transform the world. Int. J. Appl. Glass Sci. 2, 162-176. doi:10.1111/j.2041-1294.2011.00056.x

Hench, L. L., Day, D. E., Höland, W., and Rheinberger, V. M. (2010). Glass and medicine. Int. J. Appl. Glass Sci. 1, 104-107. doi:10.1111/j.20411294.2010.00001.x

Hench, L. L., and Thompson, I. (2010). Twentyfirst century challenges for biomaterials. J. R. Soc. Interface 7, S379-S391. doi:10.1098/rsif.2010.0151. focus

Höland, W., and Beall, G. H. (2012). Glass-Ceramic Technology, 2nd Edn. Hoboken: Wiley.

Huang, L., Duffrène, L., and Kieffer, J. (2004). Structural transitions in silicate glass: thermomechanical anomalies and polyamorphism. J. Non Cryst. Solids 349, 1-9. doi:10.1016/j.jnoncrysol. 2004.08.252

Hubert, M., and Faber, A. J. (2014). On the structural role of boron in borosilicate glasses. Phys. Chem. Glasses Euro. J. Glass Sci. Technol. Part B 55, 136-158.

Jantzen, C. M., Brown, K. G., and Pickett, J. B. (2010). Durable glass for thousands of years. Int. J. Appl. Glass Sci. 1, 38-62. doi:10.1111/j.2041-1294.2010. 00007.x

Jones, J. R., and Clare, A. G. (2012). Bio-Glasses. West Sussex: Wiley.

Kamitsos, E. I., and Chryssikos, G. D. (1991). Borate glass structure by Raman and infrared spectroscopies. J. Mol. Struct. 247, 1-16. doi:10.1016/00222860(91)87058-P

Kosik Williams, C., Borrelli, N. F., Senaratne, W., Wei, Y., and Petzold, O. (2014). Touchscreen surface warfare - Physics and chemistry of antimicrobial behavior of ion-exchanged silver in glass. Am. Ceram. Soc. Bull. 93, 20-24.

Lascaris, E., Hemmati, M., Buldyver, S. V., Stanley, H. E., and Angell, C. A. (2014). Search for a liquidliquid critical point in models of silica. J. Chem. Phys. 140, 224502. doi:10.1063/1.4879057

Li, H., Davis, M. J., Marker, A. J. III, and Hayden, J. S. (2010). Glass and light. Int. J. Appl. Glass Sci. 1, 63-73. doi:10.1002/app.32386

Li, L., Lin, H., Qiao, S., Zou, Y., Danto, S., Richardson, K., et al. (2014). Integrated flexible chalcognide glass photonic devices. Nat. Photon. 8, 643-649. doi:10.1038/nphoton.2014.138

Mattos, L. (2013). Usable glass strength coalition: patience, perseverance, and progress. Am. Ceram. Soc. Bull. 91, 22-29.

Mauro, J. C. (2011). Topological constraint theory of glass. Am. Ceram. Soc. Bull. 90, 31-37.
Mauro, J. C. (2013). Statistics of modifier distributions in mixed network glasses. J. Chem. Phys. 138, 12A522. doi:10.1063/1.4773356

Mauro, J. C., Ellison, A. J., and Pye, L. D. (2013a). Glass: the nanotechnology connection. Int. J. Appl. Glass Sci. 4, 64-75. doi:10.1111/ijag.12030

Mauro, J. C., Ellison, A. J., Allan, D. C., and Smedskjaer, M. M. (2013b). Topological model for the viscosity of multicomponent glass-forming liquids. Int. J. Appl. Glass Sci. 4, 408-413. doi:10.1111/ijag. 12009

Mauro, J. C., Loucks, R. J., and Gupta, P. K. (2009a). Fictive temperature and the glassy state. J. Am. Ceram. Soc. 92, 75-86. doi:10.1111/j.1551-2916. 2008.02851.X

Mauro, J. C., Yue, Y. Z., Ellison, A. J., Gupta, P. K., and Allan, D. C. (2009b). Viscosity of glass-forming liquids. Proc. Natl. Acad. Sci. U.S.A. 106, 19780-19784. doi:10.1073/pnas.0911705106

Mauro, J. C., Allan, D. C., and Potuzak, M. (2009c). Nonequilibrium viscosity of glass. Phys. Rev. B 80 094204. doi:10.1103/PhysRevB.80.094204

Mauro, J. C., Loucks, R. J., Varshneya, A. K., and Gupta, P. K. (2008). Enthalpy landscapes and the glass transition. Sci. Model. Simul. 15, 241-281. doi:10.1007/s10820-008-9092-2

Mauro, J. C., Philip, C. S., Vaughn, D. J., and Pambianchi, M. S. (2014). Glass science in the United States: current status and future directions. Int. J. Appl. Glass Sci. 5, 2-15. doi:10.1111/ijag. 12058

Mauro, J. C., and Smedskjaer, M. M. (2014). Statistical mechanics of glass. J. Non Cryst. Solids 39, 41-53. doi:10.1016/j.jnoncrysol.2014.04.009

Mauro, J. C., and Zanotto, E. D. (2014). Two centuries of glass research: historical trends, current status, and grand challenges for the future. Int. J. Appl. Glass Sci. 5, 313-327. doi:10.1111/ijag.12087

McMillan, P. F. (2004). Polyamorphic transformations in liquids and glasses. J. Mater. Chem. 14, 1506-1512. doi:10.1063/1.4790404

Micoulaut, M., and Phillips, J. C. (2007). Onset of rigidity in glasses: from random to self-organized networks. J. Non Cryst. Solids 353, 1732-1740. doi:10.1016/j.jnoncrysol.2007.01.078

Mysen, B. O., and Richet, P. (2005). Silicate Glasses and Melts. Amsterdam: Elsevier.

Pantano, C. G., Dove, D. B., and Onoda, G. Y. (1975). Glass surface analysis by Auger electron spectroscopy. J. Non Cryst. Solids 19, 41-53. doi:10. 1016/0022-3093(75)90068-X

Phillips, J. C. (1996). Stretched exponential relaxation in molecular and electronic glasses. Rep. Prog. Phys. 59, 1133-1207. doi:10.1088/0034-4885/59/9/ 003

Pilkington, L. A. B. (1969). The float glass process. Proc. R. Soc. Lond. 314, 1-25. doi:10.1098/rspa.1969.0212

Pinckney, L. R. (1999). Transparent, high strain point spinel glass-ceramics. J. Non Cryst. Solids 255, 171-177. doi:10.1016/S0022-3093(99)00368-3

Potuzak, M., Mauro, J. C., Kiczenski, T. J., Ellison, A. J., and Allan, D. C. (2010). Communication: resolving the vibrational and configurational contributions to thermal expansion in isobaric glass-forming systems. J. Chem. Phys. 133, 091102. doi:10.1063/1. 3481441

Quinn, G. D. (2012). A history of the fractography of glasses and ceramics. Fractogr. Glass
Ceram. VI. Ceram. Trans. 230, 1-55. doi:10.1002/ 9781118433010.ch1

Rahaman, M. N., Day, D. E., Bal, B. S., Fu, Q., Jung, S. B., Bonewald, L. F., et al. (2011). Bioactive glass in tissue engineering. Acta Biomater. 7, 2355-2373. doi:10.1016/j.actbio.2011.03.016

Richardson, K., Krol, D., and Hirao, K. (2010). Glasses for photonic applications. Int. J. Appl. Glass Sci. 1, 74-86. doi:10.1111/j.2041-1294.2010.00008.x

Rufflé, B., Guimbretière, G., Courtens, E., Vacher, R., and Monaco, G. (2006). Glass-specific behavior in the damping of acousticlike vibrations. Phys. Rev. Lett. 96, 045502. doi:10.1103/PhysRevLett.96. 045502

Schroers, J. (2013). Bulk metallic glasses. Phys. Today 66, 32-37. doi:10.1063/PT.3.1885

Shi, Y., Luo, J., Yuan, F., and Huang, L. (2014). Intrinsic ductility of glassy solids. J. Appl. Phys. 115, 043528. doi:10.1063/1.4862959

Smedskjaer, M. M., Mauro, J. C., Sen, S., and Yue, Y. Z. (2010). Quantitative design of glassy materials using temperature-dependent constraint theory. Chem. Mater. 22, 5358-5365. doi:10.1021/ cm1016799

Smedskjaer, M. M., Mauro, J. C., Youngman, R. E., Hogue, C. L., Potuzak, M., and Yue, Y. Z. (2011). Topological principles of borosilicate glass chemistry. J. Phys. Chem. B 115, 12930-12946. doi:10. 1021/jp208796b

Varshneya, A. K. (2006). Fundamentals of Inorganic Glasses, 2nd Edn. Sheffield: Society of Glass Technology.

Varshneya, A. K. (2010). Chemical strengthening of glass: lessons learned and yet to be learned. Int J. Appl. Glass Sci. 1, 131-142. doi:10.1111/j.20411294.2010.00010.x

Wallenberger, F. T., and Smrcek, A. (2010). The liquidus temperature: its critical role in glass manufacturing. Int. J. Appl. Glass Sci. 1, 151-163. doi:10.1111/j.2041-1294.2010.00015.x

Watanabe, T., Yatsuda, K., Yao, Y., Yano, T., and Matuura, T. (2010). Innovative in-flight glassmelting technology using thermal plasmas. Pure Appl. Chem. 82, 1337-1351. doi:10.1351/PACCON-09-09-19

Welch, R. C., Smith, J. R., Potuzak, M., Guo, X., Bowden, B. F., Kiczenski, T. J., et al. (2013). Dynamics of glass relaxation at room temperature. Phys Rev. Lett. 110, 265901. doi:10.1103/PhysRevLett. 110.265901

White, J. E., and Day, D. E. (1994). Rare earth aluminosilicate glasses for in vivo radiation delivery. Key Eng. Mater. 94, 181-208. doi:10.4028/www. scientific.net/KEM.94-95.181

Wiederhorn, S. M., Fett, T., Guin, J.-P., and Ciccotti, M. (2013). Griffith cracks at the nanoscale. Int. J. Appl. Glass Sci. 4, 76-86. doi:10.1111/ijag.12025

Wondraczek, L., and Mauro, J. C. (2009). Advancing glasses through fundamental research. J. Euro. Ceram. Soc. 29, 1227-1234. doi:10.1073/pnas. 1320235110

Wondraczek, L., Mauro, J. C., Eckert, J., Kühn, U., Horbach, J., Deubener, J., et al. (2011). Towards ultrastrong glasses. Adv. Mater. 23, 4578-4586. doi:10.1002/adma.201102795

Youngman, R. E. (2014). Glimpsing glass structure under pressure. Science 345, 998-999. doi:10.1126/ science. 1258785 
Yu, C. C., and Freeman, J. J. (1987). Thermal conductivity and specific heat of glasses. Phys. Rev. B 36, 7620-7624. doi:10.1103/PhysRevB.36.7620

Yue, Y.-Z. (2008). Characteristic temperatures of enthalpy relaxation in glass. J. Non Cryst. Solids 354, 1112-1118. doi:10.1016/j.jnoncrysol.2006.11.027

Zakery, A., and Elliott, S. R. (2003). Optical properties and applications of chalcogenide glasses: a review. J. Non Cryst. Solids 330, 1-12. doi:10.3390/ molecules 18055373

Zanotto, E. D. (2010). A bright future for glassceramics. Am. Ceram. Soc. Bull. 89, 19-27.

Zanotto, E. D. (2013). Glass crystallization research - a 36-year retrospective. Part I, Fundamental studies. Int. J. Appl. Glass Sci. 4, 105-116. doi:10.1111/ijag. 12022
Zhang, C., Hu, L., Yue, Y., and Mauro, J. C. (2010). Fragile-to-strong transition in metallic glass-forming liquids. J. Chem. Phys. 133, 014508. doi:10.1063/1.3457670

Zheng, Q., Potuzak, M., Mauro, J. C., Smedksjaer, M. M., Youngman, R. E., and Yue, Y. (2012). Composition-structure-property relationships in boroaluminosilicate glasses. J. Non Cryst. Solids 358, 993-1002. doi:10.1016/j.jnoncrysol. 2012.01.030

Conflict of Interest Statement: The author declares that the research was conducted in the absence of any commercial or financial relationships that could be construed as a potential conflict of interest.
Received: 23 September 2014; accepted: 24 September 2014; published online: 14 October 2014.

Citation: Mauro JC (2014) Grand challenges in glass science. Front. Mater. 1:20. doi: 10.3389/fmats.2014.00020

This article was submitted to Glass Science, a section of the journal Frontiers in Materials.

Copyright (C) 2014 Mauro. This is an open-access article distributed under the terms of the Creative Commons Attribution License (CC BY). The use, distribution or reproduction in other forums is permitted, provided the original author(s) or licensor are credited and that the original publication in this journal is cited, in accordance with accepted academic practice. No use, distribution or reproduction is permitted which does not comply with these terms. 